\title{
Genome Resource for Elsinoë batatas, the Causal Agent of Stem and Foliage Scab Disease of Sweet Potato
}

\author{
Xinxin Zhang, Hongda Zou, Yiling Yang, Boping Fang, and Lifei Huang ${ }^{\dagger}$ \\ Crop Research Institute, Guangdong Academy of Agricultural Sciences, Guangdong Provincial Key \\ Laboratory of Crops Genetics and Improvement, Guangzhou, Guangdong, 510640, China
}

Abstract

Elsinoë batatas is a phytopathogenic fungus causing stem and foliage scab disease of sweet potato. At present, there is no reference genome available for $E$. batatas, limiting basic research for the pathogen. The present study applied the Nanopore single-molecule sequencing technology to sequence the $E$. batatas genome. This study reports the first high-quality genome sequence of $E$. batatas, with a total contig size of $26.49 \mathrm{Mb}, 50.8 \%$ $\mathrm{GC}$ content, and an $\mathrm{N}_{50}$ of $2,546,814 \mathrm{bp}$. The sequences obtained serve as a reference for analysis of $E$. batatas isolates and provide a resource to better understand the biology of stem and foliage scab disease of sweet potato.

\section{Genome Announcement}

The stem and foliage scab disease caused by Elsinoë batatas is one of the most prevalent and destructive diseases of sweet potato (Clark et al. 2013). The disease was first reported in Taiwan, China and currently is widely distributed throughout Southeast Asia, Japan, Brazil, and the Pacific Islands (Ames et al.1997; Goto 1937; Jenkins and Viegas 1943). Infected leaves are often severely distorted and smaller. Lesions also occur on petioles and stems, causing distortion and twisting (Jenkins and Viegas 1943). The growing points of the vines may become necrotic. Yield losses due to stem and foliage scab can be over 50\% (Ramsey et al. 1988). Of note, the disease is most severe in regions where rain, mist, and dews are prevalent. Most provinces in southern China record high rainfall levels in summer, which often exacerbate the E. batatas infection (Fang et al. 2004).

In 2019, E. batatas CRI-CJ2 was isolated from infected sweet potato stems in Guangzhou City, Guangdong Province, China. Subsequently, the pathogen was confirmed to be $E$. batatas using internal transcribed spacer and translation elongation factor $1-\alpha$ gene sequencing analyses. Only a few genomic resources are available for Elsinoë spp. (Li et al. 2020; Shanmugam et al. 2020). In this study, the $E$. batatas genome was sequenced by Nanopore single-molecule technology based on long-read sequencing.

Mycelial tissue of $E$. batatas was grown on potato dextrose agar at $25^{\circ} \mathrm{C}$ for 14 days. Subsequently, mycelial tissue along with media was excised from plates and blended with potato dextrose broth (Difco) at 50\% concentration. The mycelial tissue was grown with constant shaking (190 rpm) at $25^{\circ} \mathrm{C}$ for 5 days. Genomic DNA was extracted using a Qiagen genomic tip100/G DNA isolation kit (Qiagen Inc., Hilden, Germany) and used for Nanopore and Illumina sequencing. The sequencing protocol was according to the instruction program of the PromethION DNA sequencer (Oxford Nanopore, Oxford, U.K.). DNA quality and concentration were assessed using $0.35 \%$ agarose gel electrophoresis and Qubit 3.0 fluorimeter (Invitrogen, Carlsbad, CA, U.S.A.). Large fragments of DNA were recycled by a BluePippin automatic nucleic acid recovery system. DNA libraries were constructed using the DNA-PCR Sequencing Kit
Funding

Support was provided by the National Sweet potato Industry Technical System (CARS-10-B-05 and CARS-10-C-17), Key-Area Research and Development Program of Guangdong Province (2020B020219001), Sweet Potato Potato Innovation Team of Modern Agricultural Industry Technology System in Guangdong Province (2020KJ111), and Science and Technology Planning Project of Guangdong (2018A050506053).

\section{Keywords}

Elsinoë batatas, fungal pathogens, genome, genomics, microbe-genome sequencing, Nanopore single molecule sequencing, sweet potato scab

\footnotetext{
${ }^{\dagger}$ Corresponding author: L. F. Huang; huanglifei@gdaas.cn
}

The author(s) declare no conflict of interest.

Accepted for publication 12 October 2021. 
Table 1. Genome statistics of Elsinoë batatas isolate CRI-CJ2

$\begin{array}{lc}\text { Feature } & \text { E. batatas } \\ \text { Depth of Nanopore sequence } & 166.42 \times \\ \text { Depth of Illumina sequence } & 168.31 \times \\ \text { Assembly size (bp) } & 26,493,939 \\ \text { Number of contigs (bp) } & 13 \\ N_{50} \text { length(bp) } & 2,546,814 \\ N_{90} \text { length (bp) } & 1,678,128 \\ \text { Contig maximum (bp) } & 3,686,497 \\ \text { GC content (\%) } & 51 \\ \text { BUSCO completeness (\%) } & 97 \\ \text { Repeat rate (\%) } & 15 \\ \text { Annotation } & \\ \text { Predicted protein-coding gene } & 9,521 \\ \text { Annotated nonredundant protein sequences } & 8,447 \\ \text { Secreted proteins } & 649 \\ \text { Secreted carbohydrate-active enzyme } & 506 \\ \text { Pathogen-host interaction proteins } & 2,594 \\ \text { GenBank accession number } & \text { JAESVG000000000 }\end{array}$

${ }^{a}$ Benchmarking universal single-copy orthologs.

(SQK-LSK 109), followed by sequencing by Biomarker Technologies (China). For functional annotation of predicted protein-coding genes, we compared their protein against the gene ontology (GO) (Ashburner et al. 2000), Kyoto Encyclopedia of Gene and Genomes (KEGG) (Kanehisa et al. 2004), eukaryotic orthologous groups (KOG) (Tatusov et al. 2000), GenBank nonredundant (nr) (Deng et al. 2006), and Swiss-Prot (Boeckmann et al. 2003) databases.

In total, 564,044 raw reads $(4,760,199,650 \mathrm{bp})$ were generated, then filtered to remove short reads (length $<2 \mathrm{~kb}$ ), reads with low-quality bases, and adapter sequences. Finally, 354,637 high-quality reads with 4,409,358,511 bp (4.41 G) of data representing 166-fold (166x) coverage of the genome were obtained and assembled using wtdbg v2.2 (Ruan and Li 2019). The assembled genome was further corrected using Pilon v1.22 (Walker et al. 2014) to obtain a more accurate genome. The assembled genome was approximately 26,493,939 bp (26.49 Mb) long in 13 scaffolds, with an overall GC content of $50.8 \%$, The $\mathrm{N}_{50}$ value was $2,546,814 \mathrm{bp}$, the $\mathrm{N}_{90}$ was $1,678,128 \mathrm{bp}$, and the longest scaffold contained 3,686,497 bp (Table 1).

To assess the genome assembly quality, $2 \times 350$-bp Illumina paired-end sequencing was performed on an Illumina HiSeq2500 platform (Illumina, San Diego, CA, U.S.A.). Genomic DNA sequencing libraries were prepared using an SQK-LSK109 Ligation Sequencing Kit. Illumina reads representing 168-fold coverage of the genome were aligned using the Burrows-Wheeler alignment tool (Li and Durbin 2009). In total, $99.27 \%$ of the clean reads were mapped to the $E$. batatas genome assembly, indicating the accuracy of the Nanopore data in genome assembly.

Completeness of assembly was verified by benchmarking universal single-copy orthologs (BUSCO v5.2.2) (Simão et al. 2015), based on 3,786 conserved genes among members of class Dothideomycetes, and revealed $94.8 \%$ completeness, with $0.3 \%$ duplication and six fragmentations. Based on the constructed repeat sequence database, 3,848,344 bp (3.85 Mb) repeat sequences accounting for $14.53 \%$ of the genome assembly were detected by RepeatMasker v4.0.6 (Tarailo-Graovac and Chen 2009).

In total, 9,521 protein-coding genes were predicted through ab initio-based, homolog-based, and RNA-sequencing-based methods integrated by EVM (version 1.1.1) (Haas et al. 2008) and modified by PASA (version 2.0.2) (Campbell et al. 2006). Among these genes, 4,896 (51\%) were classified using the KOG database, 5,717 (60\%) were mapped to the Swiss-Prot database, 3,286 (35\%) were assigned GO terms, 3,123 (33\%) were mapped to the KEGG database, 8,447 $(89 \%)$ of the predicted genes were successfully annotated using NCBl's nr database by BLAST (version 2.2.31), and 2,594 genes were predicted using the pathogen-host interaction (PHI) database v4.8 (Urban et al. 2017). The putative secreted carbohydrate-active enzymes (CAZymes) were annotated using the HMMER package (Eddy 1998), revealing 506 genes encoding CAZymes in CRI-CJ2. Meanwhile, 858 proteins were predicted to encode secreted proteins using SignalP 4.0 (Petersen et al. 2011).

The draft genome sequence has been deposited at GenBank under BioProject PRJNA645248 and BioSample SAMN17204113. Meanwhile, the Whole-Genome Shotgun project has been deposited at the DNA Data Bank of GenBank under accession number JAESVG000000000. Data 
has also been deposited in the Sequence Read Archive (SRA) database under SRA accession SRR13342287 and SRR13342288. The $E$. batatas isolate used in this study is available at the Agricultural Culture Collection of China (ACCC) in Beijing under the accession number ACCC 39729 and at the Crops Research Institute Guangdong Academy of Agricultural Sciences in Guangzhou, China.

\section{Literature Cited}

Ames, T., Smit, N. E. J. M., Braun, A. R., O’Sullivan, J. N., and Skoglund, L. G. 1997. Foliar and stem diseases caused by fungi. Page 78 in: Sweetpotato: Major Pests, Diseases, and Nutritional Disorders. International Potato Center (CIP), Lima, Peru.

Ashburner, M., Ball, C. A., Blake, J. A., Botstein, D., Butler, H., Cherry, J. M., Davis, A. P., Dolinski, K., Dwight, S. S., Eppig, J. T., Harris, M. A., Hill, D. P., Issel-Tarver, L., Kasarskis, A., Lewis, S., Matese, J. C., Richardson, J. E., Ringwald, M., Rubin, G. M., and Sherlock, G. 2000. Gene ontology: Tool for the unification of biology. Nat. Genet. 25:25-29.

Boeckmann, B., Bairoch, A., Apweiler, R., Blatter, M.-C., Estreicher, A., Gasteiger, E., Martin, M. J., Michoud, K., O'Donovan, C., Phan, I., Pilbout, S., and Schneider, M. 2003. The SWISS-PROT protein knowledgebase and its supplement TrEMBL in 2003. Nucleic Acids Res. 31:365-370.

Campbell, M. A., Haas, B. J., Hamilton, J. P., Mount, S. M., and Buell, C. R. 2006. Comprehensive analysis of alternative splicing in rice and comparative analyses with Arabidopsis. BMC Genomics 7:327.

Clark, C. A., Ferrin, D. M., Smith, T. P., and Holmes, G. J. 2013. Leaf and stem scab. Page 26 in: Compendium of Sweetpotato Diseases, Pests, and Disorders. American Phytopathological Society, St. Paul, MN, U.S.A.

Deng, Y. Y., Li, J. Q., Wu, S. F., Zhu, Y. P., Chen, Y. W., and He, F. C. 2006. Integrated $\mathrm{nr}$ database in protein annotation system and its localization. Comput Eng. 32:71-74.

Eddy, S. R. 1998. Profile hidden Markov models. Bioinformatics 14:755-763.

Fang, S. M., Ke, Y. Q., Huang, Ch. M., and Zhang, Y. J. 2004. The evaluation of resistance and analysis of resistant mechanism of sweet potato varieties to leaf scab disease. Acta Phytopathol. Sin. 31:38-44.

Goto, K. 1937. Outbreak of shoot scab of sweet potato in Amami Islands. Ann. Phytopathol. Soc. Jpn. 7:143-145.

Haas, B. J., Salzberg, S. L., Zhu, W., Pertea, M., Allen, J. E., Orvis, J., White, O., Buell, C. R., and Wortman, J. R. 2008. Automated eukaryotic gene structure annotation using EVidenceModeler and the Program to Assemble Spliced Alignments. Genome Biol. 9:R7.

Jenkins, A. E., and Viegas, A. P. 1943. Stem and foliage scab of Sweet Potato (Ipomoea batatas). J. Wash. Acad. Sci. 33:244-249.
Kanehisa, M., Goto, S., Kawashima, S., Okuno, Y., and Hattori, M. 2004. The KEGG resource for deciphering the genome. Nucleic Acids Res. 32:D277-D280.

$\mathrm{Li}, \mathrm{H}$., and Durbin, R. 2009. Fast and accurate short read alignment with BurrowsWheeler Transform. Bioinformatics 25:1754-1760.

Li, Z., Fan, Y., Chang, P., Gao, L., and Wang, X. 2020. Genome Sequence Resource for Elsinoë ampelina, the Causal Organism of Grapevine Anthracnose. Mol. Plant-Microbe Interact. 33:576-579.

Petersen, T. N., Brunak, S., von Heijne, G., and Nielsen, H. 2011. SignalP 4.0: Discriminating signal peptides from transmembrane regions. Nat. Methods 8:785786.

Ramsey, M. D., Vawdrey, L. L., and Hardy, J. 1988. Scab (Sphaceloma batatas) a new disease of sweet potatoes in Australia: Fungicide and cultivar evaluation. Aust. J. Exp. Agric. 28:137-141.

Ruan, J., and Li, H. 2019. Fast and accurate long-read assembly with wtdbg2. Nat. Methods 17:155-158.

Shanmugam, G., Jeon, J., and Hyun, J. W. 2020. Draft genome sequences of Elsinoë fawcettii and Elsinoë australis causing scab diseases on citrus. Mol. Plant-Microbe Interact. 33:135-137.

Simão, F. A., Waterhouse, R. M., loannidis, P., Kriventseva, E. V., and Zdobnov, E. M. 2015. BUSCO: Assessing genome assembly and annotation completeness with single-copy orthologs. Bioinformatics 31:3210-3212.

Tarailo-Graovac, M. and Chen, N. 2009. Using RepeatMasker to identify repetitive elements in genomic sequences. Curr. Protoc. Bioinf. 25:4.10.1-4.10.14.

Tatusov, R. L., Galperin, M. Y., Natale, D. A., and Koonin, E. V. 2000. The COG database: A tool for genome-scale analysis of protein functions and evolution. Nucleic Acids Res. 28:33-36.

Urban, M., Cuzick, A., Rutherford, K., Irvine, A., Pedro, H., Pant, R., Sadanadan, V., Khamari, L., Billal, S., Mohanty, S., and Hammond-Kosack, K. E. 2017. PHI-base: A new interface and further additions for the multi-species pathogen-host interactions database. Nucleic Acids Res. 45:D604-D610.

Walker, B. J., Abeel, T., Shea, T., Priest, M., Abouelliel, A., Sakthikumar, S., Cuomo, C. A., Zeng, Q., Wortman, J., Young, S. K., and Earl, A. M. 2014. Pilon: An integrated tool for comprehensive microbial variant detection and genome assembly improvement. PLoS One 9:e112963. 